\title{
3D printing and thoracoscopy assisted MIPO in treatment of long-range comminuted rib fractures, a case report
}

\author{
Xuetao Zhou, Dongsheng Zhang ${ }^{*}$, Zexin Xie, Menghui Chen, Yang Yang, Zheng Liang and Guoliang Zhang
}

\begin{abstract}
Background: To investigate the application of 3D printing technology combined with percutaneous Minimally Invasive Plate Oseoynthesis (MIPO) and thoracoscopic techniques in the treatment of long comminuted rib fractures.

Case presentation: One case of multiple rib fractures with abnormal respiratory disease (including rib 3 and 4 of long comminuted fractures) due to a fall injury was selected. The 3D model of comminuted rib fracture was reconstructed and printed according to the thin-layer $C T$ scan results. After the fracture model was restored to the normal rib anatomy, the metal plate was accurately shaped according to the 3D rib shape.

Conclusions: 3D printing technology combined with MIPO technology under thoracoscopy in the minimally invasive treatment of long-range comminuted rib fractures, greatly reduced the time and improved the accuracy of intraoperative fixation, reduced the difficulty of surgery, patient injury, and perfectly reconstructed the chest wall. Application of the 3D printing technique to make the rib model and pre-mold the metal plate combined the thoracoscopic MIPO technology provides less invasive and accurate individualized treatment for complex rib fractures.
\end{abstract}

Keywords: 3D printing, Minimally invasive plate Oseoynthesis (MIPO), Multiple rib fractures, Thoracoscope

\section{Background}

The traditional treatment of rib fractures is mainly conservative treatment [1].In recent years, with the continuous availability of new rib internal fixation materials and equipment, the development of surgical treatment has been greatly promoted, and the operation has also been simplified and minimally invasive [2]. The indications for internal fixation of rib fractures have also been constantly updated and broadened [3], but high rib fractures, especially behind the scapula, are complex and challenging issues for the surgeon. Traditional operation methods are not only difficult to operate, but also cause great damage to patients. However; the MIPO technique does not break the skin of the fracture end, and fix the fracture through the periosteal subcutaneous tunnel without destroying the blood supply of periosteum. With the rapid development of minimally invasive techniques in various medical fields, the use of orthopaedic MIPO technology and thoracoscopic

\footnotetext{
* Correspondence: ZDS9999@163.com

Department of Cardiothoracic Surgery, The Third Hospital of Shijiazhuang City, Shijiazhuang 050000, China
}

technology, combined with 3D printing technology to rebuild the 3D model, preoperatively shaping the metal bone plate brings great convenience to surgery and greatly reduces patient injury.

\section{Case presentation \\ Typical case}

The patient was a 61-year-old man with multiple left rib fractures (1-6 ribs), left pneumothorax, left lung contusion, and left thoracic subcutaneous emphysema due to a fall injury. The examination showed a partial depression in the left front rib and abnormal breathing (see Fig. 1).

Admission chest CT examination: 1-6 rib fractures on the left side (of which 3, 4 ribs are long comminuted fractures (see Fig. 2)); left pneumothorax, left traumatic wet lung; a small amount of liquid pneumothorax on the left side.

Patient was given early chest straps, multiparametric monitoring, analgesia, and oxygen therapy. The chest pain was still severe. The visual analogue scale scored $7-8$ points for the pain at rest and 9 points for the cough. 


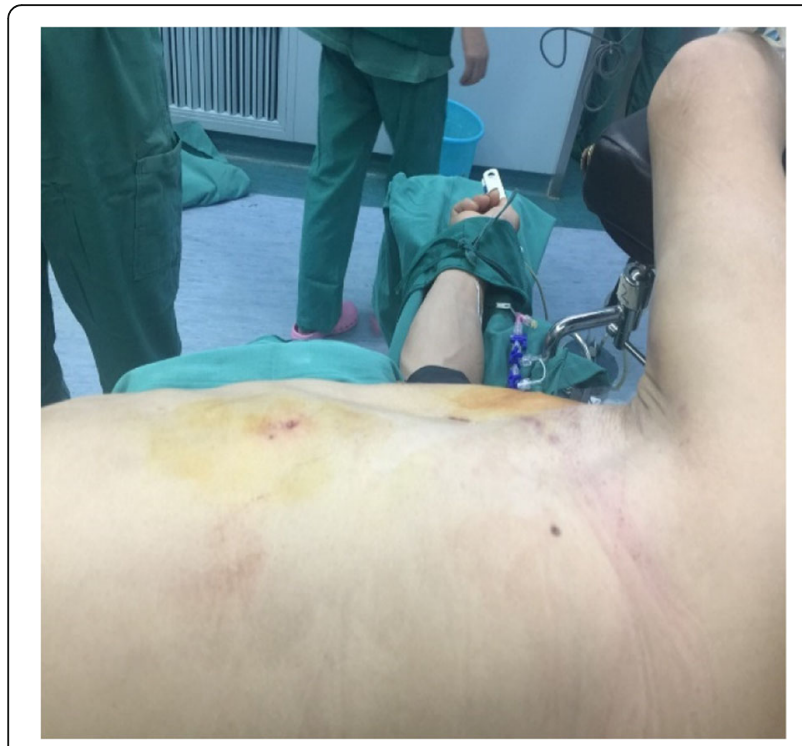

Fig. 1 Observation of the patient and his rib fractures. Patient's anterior chest wall depression.

\section{Surgical methods}

Physical examination revealed that the left chest wall was recessed and abnormally breathed. The CT scan of the rib showed a long comminuted fracture of 3 and 4 ribs. The key to successful operation was the reduction and fixation of these two rib fractures. A preoperative CT scan was performed to reconstruct the 3D model based on the scan results (see Fig. 3), and 3D printing technology was used to prepare 3 and 4 rib models (see

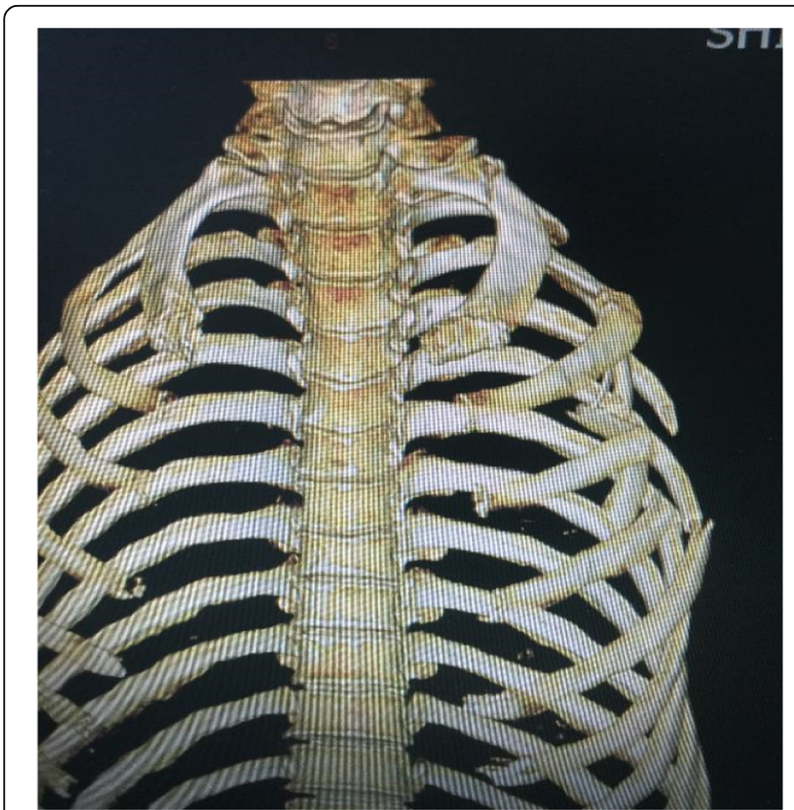

Fig. 2 Multiple rib fractures on the left side, including comminuted fractures of 3 and 4 ribs
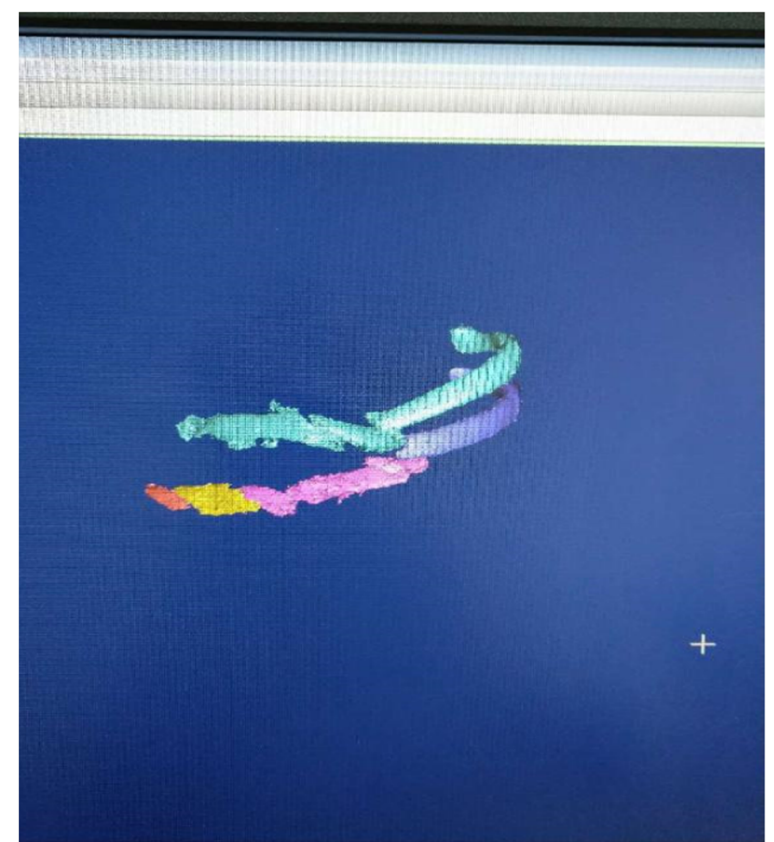

Fig. 3 Rib model Reconstruction. Reconstruction of the 3D model from CT thin-layer scan results

Fig. 4). The three D print models of each fracture segment of the two ribs were adherently reconstructed.

The two rib metal plates were separately shaped according to the reconstruction model (see Figs. 5 and 6).

The patient is scheduled to have a open reduction and internal fixation of 3-6 rib fracture. After general anesthesia, right side lying position, small incision about $8 \mathrm{~cm}$ was performed under the edge of 4 th rib underarm. The skin was sequentially incised and the subcutaneous tissue was freed layer by layer. The front of the latissimus dorsi muscle and the anterior serratus were exposed. The tunnel was

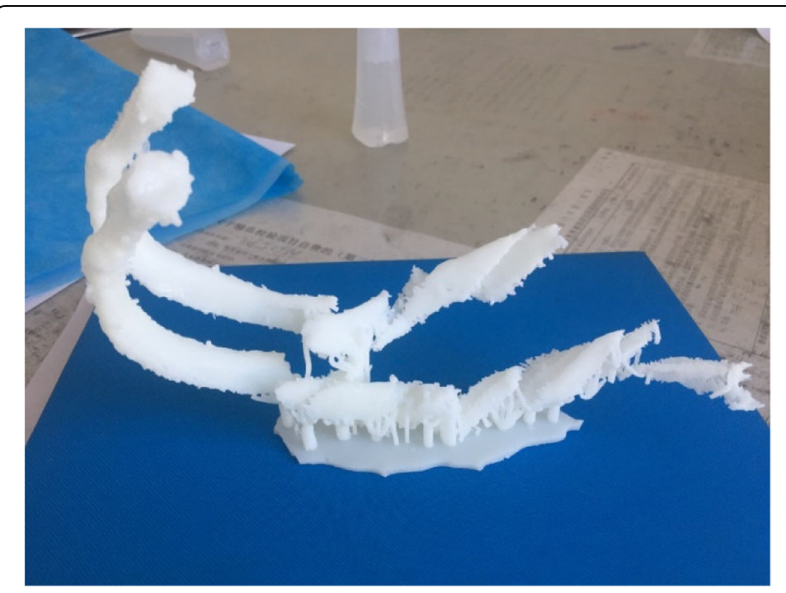

Fig. 4 Preoperative Reconstruction of the 3D model from $C T$ thinlayer scan results prepared by 3D printing technique. Preoperative $3 \mathrm{D}$ reconstruction of the $3 \mathrm{rd}$ and 4 th rib images; 3,4 rib model prepared by $3 \mathrm{D}$ printing technique. 


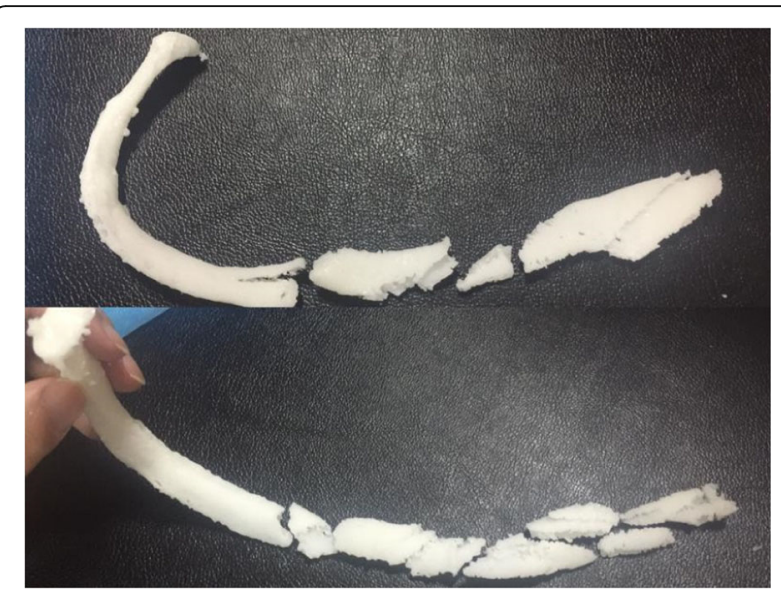

Fig. 5 3D model printing. Restoring fracture morphology; splicing a 3D printed model

established on the 3rd and 4th rib surfaces from the back of the chest and small muscles to the back of the scapula. The special long hooks lifted the scapula and exposed the scapular operation space. With assistance of endoscope, the electrocautery is useful to expose $3 \mathrm{~cm}$ outside the outermost fracture lines of the 3 and 4 ribs. The locking plate was molded on the surface of the third rib before operation, and the broken end of the non-fracture at the anterior and posterior portions of the third rib was well fitted. The distance between the two ends of the metal bone plate exceeded the fracture line to 3 nail holes distance. Under the thoracoscope, the metal plate and the ribs were temporarily fixed with long-angled forceps. The MIPO system was used to drill the holes. Two screws were implanted and locked at both ends to firmly fix the metal plate. In turn, each fracture segment was reset and drilled and secured to a metal plate. The fourth rib is fixed in the same way. Intraoperative image (Figs. 7, and 8). 5, 6 rib fractures given to fix the ribs, not the content of this article, not elaborated.

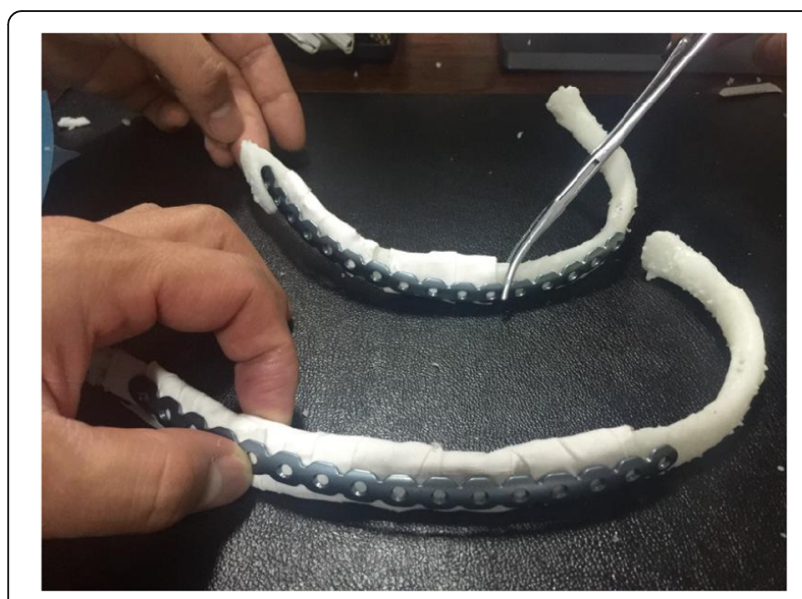

Fig. 6 Shaping the metal plate according to the model
Sufficient to stop the bleeding, the wound was given to leave a negative pressure drainage tube. After a routine thoracoscopic probe of the chest cavity, a closed thoracic drainage tube was placed posterior to the 7th intercostal space and the incision was closed layer by layer. After the chest wall is well-shaped. Three days after surgery review the map (Fig. 9).

\section{Discussion and conclusions}

Rib fractures are most common in chest injuries, accounting for 40 to $60 \%$ thoracic injuries [4]. Surgical treatment of complex rib fractures has become a routine method. However, for long segment, superior, and comminuted rib fractures, due to the complex anatomical location, conventional surgical operations are more difficult and patients have greater surgical injury.

The thorax is a complex three-dimensional structure, and the ribs also have relatively special anatomical characteristics. In addition to the conventional anatomical parameters such as length and width, bending angle and longitudinal twisting angle are also important parameters. Although the commonly used fixtures have been greatly improved, it is still difficult to fully comply with the normal physiological and anatomical characteristics of three-dimensional bending and twisting of the ribs. For long segments and crushed rib fractures, the ribs have been severely deformed, and the basis for the shaping of the fixed material has been lost, causing great difficulties for surgery, and repeated adjustment of fixed materials increases the operation time and trauma. In particular, if the poor shape of the internal fixation is poor and the two ends of the fracture are poorly attached, the internal fixation body will have a distorted tension, and the ribs are weak and continuous moving. All these will easily lead to unscrewing and fixation (see Fig. 10).

The 3D printing technology has already brought about big improvements in various fields of medicine, especially orthopaedics [5-7] and also thoracic surgery

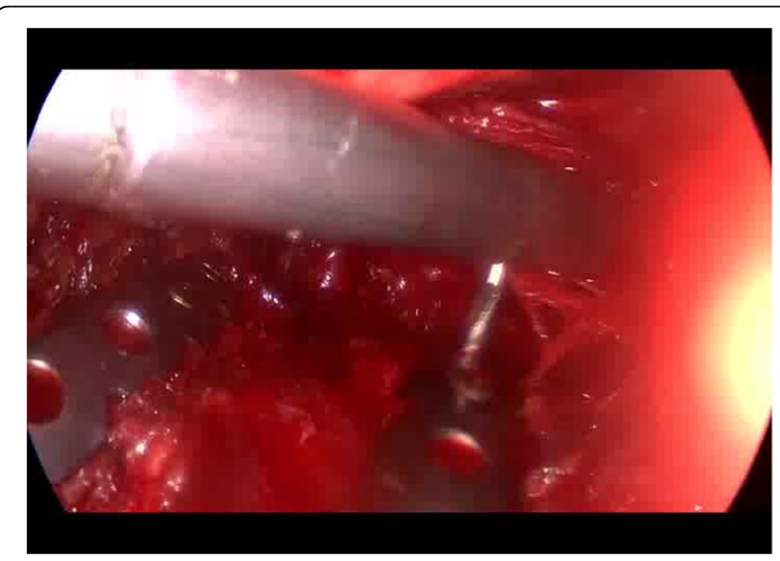

Fig. 7 Intraoperative thoracoscopic assisted MIPO. The screws were drilled by the Intraoperative thoracoscopic assisted MIPO technique 


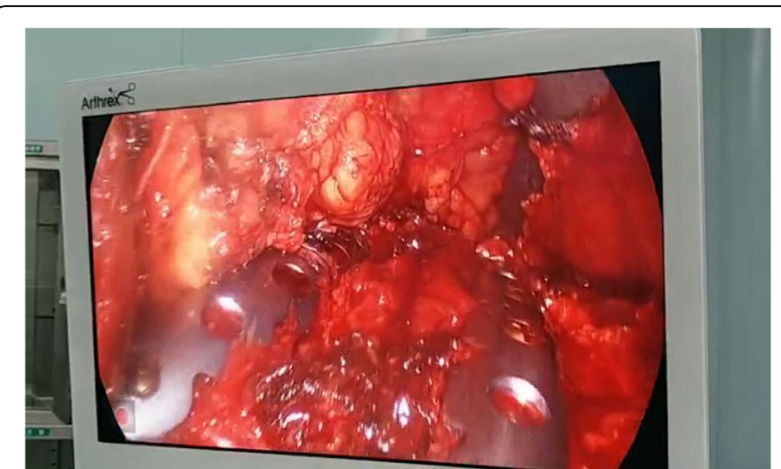

Fig. 8 thoracoscopic observation of the ribs. The shape of the 3rd and 4 th rib bone plates after being fixed

[8-11]. This study used 3D printing technology, preoperative CT thin-layer scanning, reconstruction of 3D models based on scan results, and preparation of rib models using $3 \mathrm{D}$ printing techniques. The fractures were modeled before the reconstruction of the normal rib morphology. Reshape the ribbed metal plate according to the reconstruction model. During the operation, the shaped metal plate is fixed on the ribs outside the fracture line to establish the basic frame, and then the other

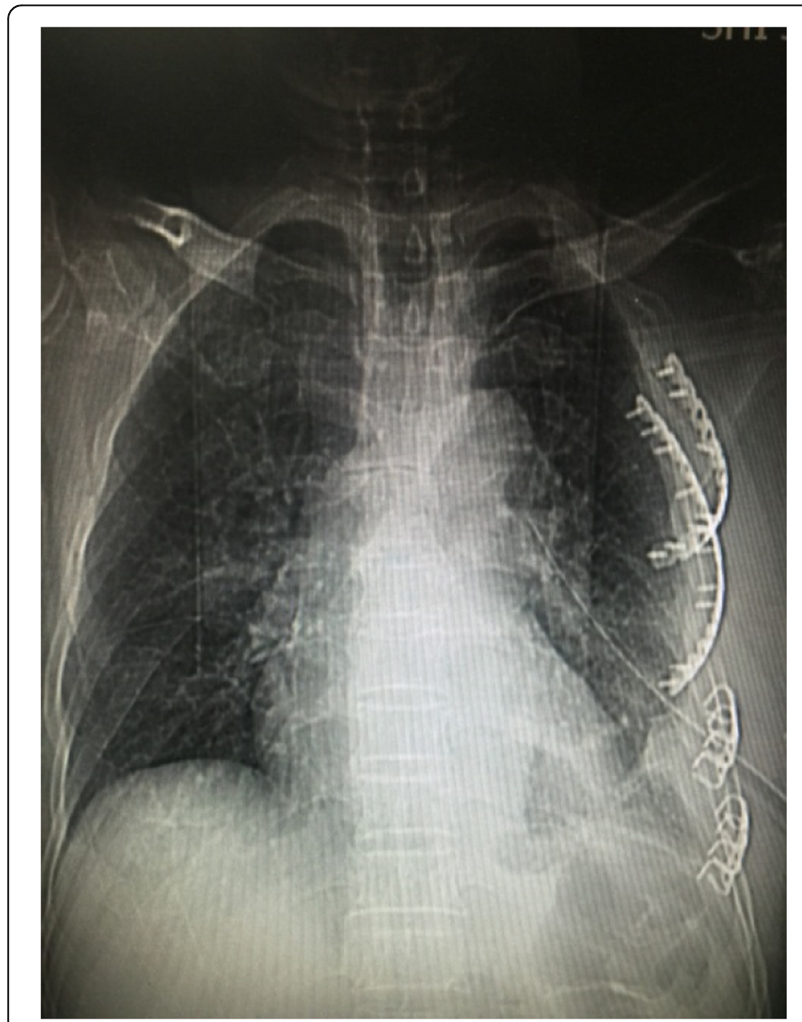

Fig. 9 post-operation review of the chest radiograph. In postoperation review of the chest radiograph, the shape of the internal fixation is intact and completely symmetrical with the contralateral ribs

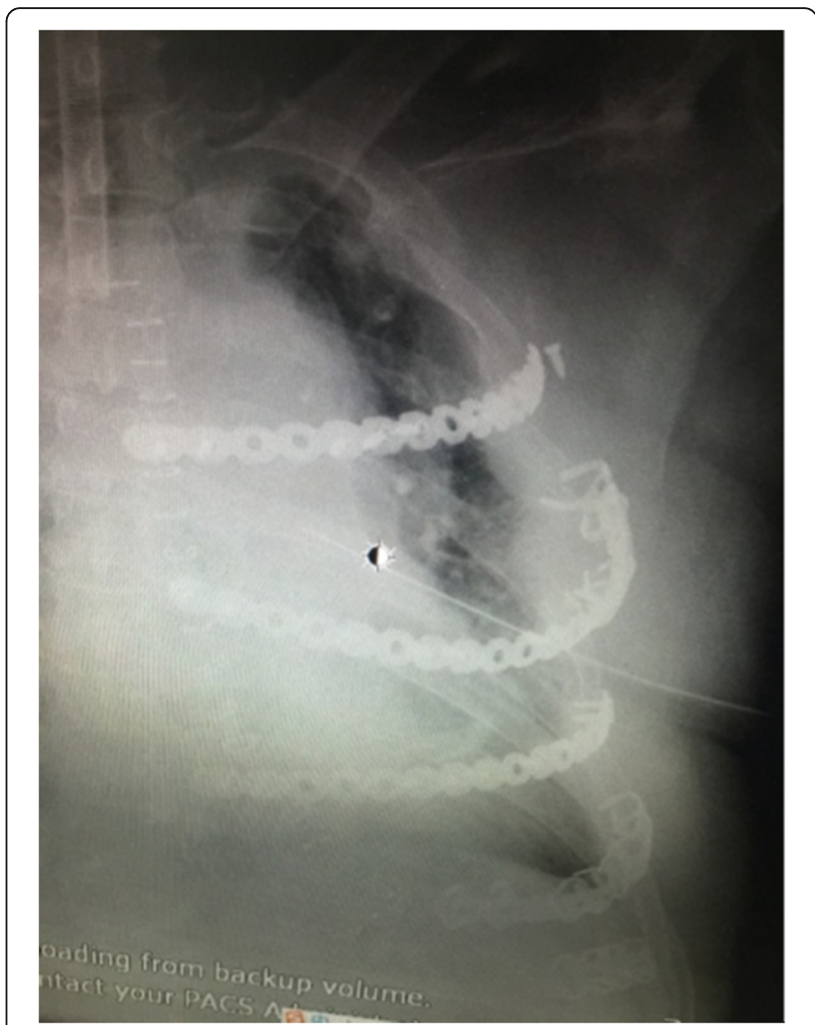

Fig. 10 visualization of the fixed ribs. In another patient, the detachment screws are visible at the back of the uppermost metal plate. The second metal plate is not well-shaped. The posterior and ribs are poorly applied. In order to prevent falling off, it is fixed by the embracing fixator

fracture segments are respectively reset and fixed on the metal plate, which saves time and labor, and is satisfactory in shaping.

Especially for long upper rib fractures, due to the anatomical relationship between scapula and other anatomies, traditional surgical methods are difficult and traumatic [12]. With the help of thoracoscopy, only a small space is needed to perfectly reveal the area under the scapula, and the fractured end is well exposed. It is easier to complete the rib drilling fixation with the MIPO system [2], especially in combination with the above-mentioned 3D printing technology for pre-shaping the steel plate. And individualized treatments provide new methods.

In summary, the combination of 3D printing technology and MIPO technology in the minimally invasive treatment of long comminuted rib fractures assisted by thoracoscopy, greatly reduced the time and improved the accuracy of intraoperative fixed plastics, reducing the difficulty of surgery and patient injury. The method still needs more clinical experience to provide better services for the majority of patients. 


\section{Abbreviations}

MIPO: Minimally Invasive Plate Oseoynthesis

\section{Acknowledgements}

N/A.

\section{Funding}

2019 Medical Science Research Key Project Program Directory of Hebei

Province.

\section{Availability of data and materials}

All data generated or analysed during this study are included in this published article.

\section{Authors' contributions}

ZXT, XZX, CMH, YY, ZL and ZGL analyzed, interpreted the patient data and prepared the 3D printing. ZDS led the thoracoscopy assisted MIPO and was a major contributor in writing the manuscript. All authors read and approved the final manuscript.

\section{Ethics approval and consent to participate}

N/A.

\section{Consent for publication}

We have obtained consent to publish from the participant to report individual patient data (including images).

\section{Competing interests}

The authors declare that they have no competing interests.

\section{Publisher's Note}

Springer Nature remains neutral with regard to jurisdictional claims in published maps and institutional affiliations.

Received: 28 January 2019 Accepted: 1 April 2019

Published online: 29 April 2019

\section{References}

1. Mayberry JC, et al. Surveyed opinion of American trauma, orthopedic, and thoracic surgeons on rib and sternal fracture repair. J Trauma. 2009;66(3): 875-9.

2. Bemelman $\mathrm{M}$, et al. The role of minimally invasive plate Osteosynthesis in rib fixation: a review. Korean J Thorac Cardiovasc Surg. 2016;49(1):1-8.

3. Nirula R, et al. Rib fracture repair: indications, technical issues, and future directions. World J Surg. 2009;33(1):14-22.

4. Bemelman $\mathrm{M}$, et al. Rib fractures: to fix or not to fix? An evidence-based algorithm. Korean J Thorac Cardiovasc Surg. 2017;50(4):229-34.

5. Morris S. Future of 3D printing: how 3D bioprinting technology can revolutionize healthcare? Birth Defects Res. 2018;110(13):1098-101.

6. Lieben L. Regenerative medicine: the future of 3D printing of human tissues is taking shape. Nat Rev Rheumatol. 2016;12(4):191.

7. Reighard $\mathrm{CL}$, Hollister $\mathrm{S} J$, Zopf DA. Auricular reconstruction from rib to $3 \mathrm{D}$ printing. J 3D Print Med. 2018;2(1):35-41.

8. Finotello A, Marconi S, Pane B, et al. Twelve-year follow-up post-thoracic endovascular repair in type $B$ aortic dissection shown by three-dimensional printing. Ann Vasc Surg. 2019;55:309.e13-9.

9. Chen YY, Lin KH, Huang HK, et al. The beneficial application of preoperative 3D printing for surgical stabilization of rib fractures. PLoS One. 2018;13(10): e0204652.

10. Mendez A, Gomez-Ciriza G, Raboisson MJ, et al. Apical muscular ventricular septal defects: surgical strategy using three-dimensional printed model. Semin Thorac Cardiovasc Surg. 2018;30(4):450-3.

11. Li H, Qingyao B, et al. Application of 3D printing technology to left atrial appendage occlusion. Int J Cardiol. 2017;231:258-63.

12. de Jong MB, et al. Surgical Management of rib Fractures: strategies and literature review. Scand J Surg. 2014;103(2):120-5.

Ready to submit your research? Choose BMC and benefit from:

- fast, convenient online submission

- thorough peer review by experienced researchers in your field

- rapid publication on acceptance

- support for research data, including large and complex data types

- gold Open Access which fosters wider collaboration and increased citations

- maximum visibility for your research: over $100 \mathrm{M}$ website views per year

At BMC, research is always in progress.

Learn more biomedcentral.com/submissions 